\title{
Caltech wins funds for largest instrument
}

\section{Los Angeles}

CALIFORNIAN astronomers last year went a-courting for funds to build the world's largest optical telescope and last week announced they have found a sweetheart of a deal.

In what is being called the biggest private grant ever made to a scientific project, the William M. Keck Foundation of Los Angeles has pledged \$70 million to the California Institute of Technology to build a 10-metre telescope on Mauna Kea in Hawaii. The University of California will join the project by providing $\$ 2$ million for operating costs once the telescope is completed in the early 1990 s.

It is time to build a new generation of ground-based optical telescopes, said Dr Marvin L. Goldberger, president of Caltech. The five-metre Hale Telescope on Mount Palomar (operated by Caltech) "has reached its theoretical limits", he said. New technologies such as charge-coupled devices permit the Palomar instrument to collect up to 80 photons per 100 . But the maximum limit of detection efficiencies has been reached and astronomers need larger telescopes to gather more light.

The Keck Ten Meter Telescope will be four times more powerful than the Hale Telescope and will be able to detect light from objects that are 12,000 million years old, compared with Palomar's limit of 8,500 million years old.

The new instrument will use new technology to reduce cost, size and weight. Instead of a single polished mirror, the Keck Telescope will consist of $\mathbf{3 6}$ hexagonal mirrors six feet wide and three inches thick.

Each mirror will be made using a new technique called "stressed mirror polishing". A mirror blank is warped to a predetermined configuration by applied force and is then polished to a spherical surface.

After polishing, the forde is released and a mirror elastically assumes the desired non-symmetric surface. Dr Jerry Nelson, the astronomer at the University of California who developed the technique said the mirror surfaces resemble "potato chips".

The mirrors are then combined into a single light-collecting device by a computer-controlled aiming system. "We are replacing mechanical rigidity with electronic stiffening", Dr Nelson said. The computer measures the position of each mirror 300 times each second and automatically corrects the position of the array, even in high winds. The new observatory will be located at 13,600 feet on a ridge on Mauna Kea close to a number of other astronomical installations including a British telescope.
The Keck Ten Meter Telescope is probably only the first to win funds in a lineup of other large ground-based telescopes now proposed. The University of Texas has hopes of building a 7-metre instrument and the National Science Foundation has long discussed the idea of building a 15-metre telescope using four mirrors.

The Space Telescope, to be launched in 1986, should be complementary to the Keck instrument, which will have 17 times more light gathering capacity "and will be used to study in detail objects that might have been spotted by the Space Telescope", Dr Goldberger said.

The William M. Keck Foundation was formed in 1954 by the founder of Superior
Oil Company. Howard B. Keck, a son, is chairman and president of the foundation, which now has assets in excess of $\$ 500$ million. The foundation decided to give $\$ 70$ million to Caltech, foundation directors said, in a continuing spirit of helping scientific endeavours. It has, for example, given $\$ 7$ million over a period of years to the Colorado School of Mines.

The Keck Telescope was to have been called the Hoffman Telescope after Marion Hoffman, widow of a wealthy automobile importer Maximilian Hoffman, who had pledged $\$ 36$ million to the University of California to build the Ten Meter Telescope. But after Mrs Hoffman died last year, said UC president David Gardner, Caltech was approached to see if both universities could work together to raise the $\$ 85$ million needed to complete the project. The Hoffman family will decide before 1 March on continued participation, but there are some who fear that Mrs Hoffman's offer will be withdrawn.

Sandra Blakeslee

\section{White House holds the ring}

\section{Washington}

THE White House Office of Science and Technology Policy (OSTP) says, in a major statement on biotechnology regulation*, that the Recombinant DNA Advisory Committee (RAC) of the National Institutes of Health should continue to be the main overseeing body for biomedical research, and endorses the actions of the Environmental Protection Agency in moving to regulate industrial biotechnology.

The question uppermost in the minds of industrial biotechnology companies has been how the Environmental Protection Agency (EPA) would plan to use the Toxic Substance Control Act (TSCA). This act is a catch-all giving EPA the authority to control substances other than pesticides and drugs not covered by other legislation; novel microorganisms are counted as new chemical substances subject to the act's provisions.

There was some concern last year when preliminary drafts circulated by EPA indicated that TSCA could be applied to intermediates used in the manufacture of food products or drugs, which would then be subject to a 90-day notification requirement. EPA now says that such intermediates will not be reviewed under TSCA, leaving the Food and Drug Administration and the Department of Agriculture to deal with such problems as product contamination. In addition, small quantities of chemicals produced exclusively for research purposes will not be subject to the 90 -day notification requirement.

EPA has still not resolved, however, some important aspects of when a micro organism constitutes a new chemical substance. Operational definitions are used as far as possible, the guiding principle being that a new substance is produced if the manufacturing process brings together traits not normally found together in nature. But there are obvious difficulties: for example, EPA seeks comments on whether undirected mutagenesis plus artificial selection should be regarded as giving rise to a new substance. Products or organisms isolated through artificial selection alone, and plants and animals other than microorganisms, are not classed as new substances. EPA has not committed itself on notification requirements for small-scale field testing of novel microorganisms other than pesticides; an interim policy on testing microbial pesticides was announced in October (see Nature 25 October 1984, p.695).

Although satisfied that no new legislation will be needed to control the new biotechnology in the foreseeable future, OSTP does see a need for better expert advice in several federal agencies having relevant authority: "the current scientific review apparatus is not designed to respond to all the scientific issues surrounding commercialization of biotechnology". In addition to RAC, OSTP proposes four new independent expert committees, one each in EPA, the Food and Drug Administration, the Department of Agriculture and the National Science Foundation (NSF). The NSF committee would concentrate on the environmental effects of developments in biotechnology; the others would address mainly commercial applications. The work of the committees would be coordinated by a Biotechnology Science Board reporting to the assistant secretary for health.

Comments on the OSTP proposals are welcomed, and should be received before 1 April.

Tim Beardsley

*Federal Register 49, 50878-50907 (1984). 